\title{
Ecological and Anthropological Threats to Ethno-Medicinal Plant Resources and their Utilization in Maasai Communal Ranches in the Amboseli Region of Kenya
}

\author{
John Warui Kiringe
}

\begin{abstract}
Use of traditional medicine is prevalent among rural communities of Africa. They have immense knowledge on ethno-medicine but its use is rapidly diminishing partly due to lifestyle changes and exposure to Western ideologies. This study investigated threats to medicinal plant resources and knowledge on their use in a communally owned Maasai group ranch through a questionnaire and discussions. Traditional medicine was preferred over modern medicine though most members visited local health centers whenever a need arose. Knowledge of ethno-medicine was wide-spread in the community and did not appear to have been significantly impacted by formal education, Christianity or occupation but it varied by gender and among different age groups. Teaching of traditional Maasai ethno-medicine was prevalent but older members of the community felt that the younger generations generally lacked an interest in learning such traditions. The community also felt that medicinal plants harvested within the ranch had declined and attributed this to several factors including; land use changes especially introduction of agriculture, charcoal burning, over exploitation for commercial purposes, drought and increase in human population. Future research is needed to elucidate the impacts of formal education, current lifestyle changes and introduction of Christianity and Western medical care on knowledge and use of ethno-medicine. There is an urgent need to mitigate decline of locally available medicinal plant resources.
\end{abstract}

\section{Introduction}

Since time immemorial plants have been an important integral component of indigenous health remedies for most African communities (Mauarice 1993, Sindiga 1995a-e, Sindiga et al. 1995a,b). They are used to provide biologically active ingredients or compounds as a remedy for diverse illnesses and body conditions, and for the traditional spiritual significance some species hold (Farnsworth \& Soejarto 1991, Githae 1995, Maurice 1993). When administered, herbal medicine has both curative and preventive purposes (Farnsworth \& Soejarto 1991, Githae 1995). Introduction of Western medicine and medical practices in colonial Africa in the last century has become widespread, but many rural communities are still heavily dependent on traditional or indigenous plant medicine as their primary health care (Farnsworth \& Soejarto 1991, Fratkin 1996, Olayiwola 1991, Sindiga 1995a-e). In Kenya for example, nearly $90 \%$ of the population especially in the rural areas rely on herbal remedies (Ochieng' Obado \& Odera 1995, Sindiga et al. 1995a,b).

Most tribes in Africa have well elaborate pharmacopoeia and immense knowledge on indigenous health remedies which have been developed for hundreds or perhaps thousands of years. For instance, the Pokot and Turkana of Kenya are known to use nearly 118 and 67 different species of indigenous plants respectively to treat diverse types of illnesses that afflict the community (Barrow 1996). The Nilotic-speaking Samburu and the Maasai are also know to have vast knowledge on ethno-medicine,

\section{Correspondence}

John Warui Kiringe, The School for Field Studies, Center for Wildlife Management Studies, P.O. Box 27743-00506, Nairobi, KENYA.

okelinge@africaonline.co.ke or jwkiringe@yahoo.com

Ethnobotany Research \& Applications 3:231-241 (2005) 
and even to date a majority of their people who live in the rural areas are largely dependent on herbal remedies even though Western medicine has been popularized (Fratkin 1996). Through generations knowledge on identification of plant species with medicinal properties and their use have been developed (Sheldon \& Balick 1996). Among most African communities intergenerational transfer of knowledge of indigenous herbal medicine is entirely oral. This is the case for the Maasai (Sankan 1995, Sindiga 1994) one of the few tribes in Kenya that has maintained their traditional lifestyle and practices amidst a strong influence of Western culture that has seen most other communities abandon their traditions entirely. Oral transfer of knowledge of ethno-medicine was also common in other tribes like the Kikuyu, Luo, and Gussi (Ochieng' Obado \& Odera 1995, Sindiga 1995a-e, Sindiga et al. 1995a,b). However, in the last few decades these communities have nearly abandoned this form of health care and instead rely more or less on Western medicine and medical practices. This has had tremendous impact on the traditional knowledge of indigenous-based health treatment.

Even though herbalists exist in most tribes of Africa, use of common herbal remedies is generally known throughout the communities. There are however, specific individuals renowned and recognized for their skills and knowledge, and tend to practice in secrecy (Sankan 1995). In fact many traditional healers add multiple ingredients to their herbal concoctions so that anyone observing the preparation will not know which specific plant(s) provides effective and healing biological ingredients (Maurice 1993). Among the Samburu and Maasai the learned medicine men with immense knowledge on tradition medicine are called laibon (pl. oloibanok), of which there are multiple categories, and this position is passed on through kinship (Sindiga 1995a-e).

Introduction of Western culture into rural parts of Africa has had a tremendous negative impact on the role traditional medicine plays. As Western education, Christianity and increased contact with the global community become an integral part of rural communities, taboos, traditions and customs have been affected and in some instances abandoned altogether, and therefore traditional medicine may not retain the significance it once held (Sindiga 1995a-e). In addition to the gradual cultural change that currently characterizes the continent, there have been institutional efforts by colonialists to stifle traditional medicine in certain countries. The Witchcraft Act of 1925 in Kenya was enacted to outlaw practices by communities that were perceived by the colonial government to border on witchcraft (Sindiga et al. 1995a). This is an illustration of how Western influence and stigmatization of traditional African practices and beliefs can negatively impact important values of local communities.

Among the Kikuyu and Luo societies, the use of traditional medicine appears unrelated to level of literacy, financial status or gender (Sindiga et al. 1995a), but to a certain extent Christianity has had some impact. Since its introduction, most Kikuyu Christians have increasingly opposed and even stigmatized traditional practices and beliefs including use of traditional medicine. In other Kenyan communities, the impacts of Christianity are increasingly being felt as well, and even though use of ethno-medicine is still prevalent and may continue in certain tribes like the Maasai, Turkana, Pokot and other pastoralists, this may not be the case in the near future (Sindiga et al. 1995b, Wandibba 1995).

The Maasai people are known to use indigenous herbal remedies to treat and manage diverse illnesses in livestock and humans, and this knowledge has been acquired and entrenched in the community for many generations (Fratkin 1996, Sheldon \& Balick 1996, Sindiga 1995a-e). This has prompted the stewardship of these resources. However, in the recent past, use and knowledge of traditional medicine and practices has faced numerous tests some of which can be traced to invasion of Africa by colonialists. Apart from threatening the communities' knowledge on traditional medicine, changing lifestyles and practices (Sindiga 1995a-e) are also affecting the status of medicinal plants themselves. It is generally agreed that in the less developed countries like those of Africa, human activities are taking a serious toll on renewable resources including plant species that are valuable to rural communities (Southgate \& Sanders 1990). Deforestation is one of such activities and has led to tremendous loss of important plant resources in both the developed and developing countries.

Kuku Group Ranch where this study was done is one of the communally owned Maasai ranches in the Amboseli region. In a recent study, Kiringe (n.d.) found that $73 \%$ of its members used ethno-medicine as their primary health system even though they frequently visited local health facilities. Use and knowledge on plant herbal remedies was quite immense and the community had evolved a detailed pharmacopoeia with elaborate treatment for different types of illnesses and body conditions. There is however uncertainty about the future of their cultural beliefs and traditional practices such as use of ethno-medicine amidst the introduction of formal education, modern health care and Christianity. Another equally serious threat to their traditional values are changes in lifestyle with pressure being put on them to emulate other Kenyan communities who have embraced Western ideologies and lifestyles. Most of members are sedentary and this has significantly curtailed their traditional mobility together with their livestock. Tremendous land use changes have taken place in the recent past which has seen agriculture become popularized (Cambell et al. 2000, Eliezer 1991, Kiambi 1991), and this has the potential to undermine the conservation of important plant resources to the community. Based on these changes that appear to move swiftly across Maasai land country wide, this study aimed to investigate the impacts 


\section{Kiringe - Ecological and Anthropological Threats to Ethno-Medicinal Plant Resources and their Utilization in Maasai Communal Ranches in the}

of cultural and traditional lifestyle changes on the use and knowledge of ethno-medicine among the Maasai of Kuku Group Ranch, and to identify threats to medicinal plant resources that are found locally within the ranch.

\section{Study Area}

Kuku Group Ranch was gazette as a group ranch by the Kenya Government in 1970 following the enactment of the Group Ranches Act in 1968, and covers approximately. 96000 hectares. It is located in the Southern part of Kajiado District near the Kenya-Tanzania border (Figure 1) being one of the six communally owned group ranches by the Maasai people. The ranch is an expansive rangeland region characterized by a relatively dry and semi-arid climate or environment (Pratt \& Gwynne 1977, Republic of Kenya 1990), most of which is influenced by the Inter-tropical Convergence Zone (ITCZ) and the neighboring Mt. Kilimanjaro and Chyulu Hills. Rainfall is usually received twice a year with long rains and short rains occurring between March to May and November to December respectively (Awere-Gyekye 1996, Katampoi et al. 1990). The rest of the months are relatively dry and incase there are rains, they are relatively poor, low in amount and of a shorter duration compared to the two main rainfall peaks. Overall, rainfall in the entire region is very low varying between $250-600 \mathrm{~mm}$ annually and is highly unpredictable, spotty and erratic (Awere-Gyekye 1996, Republic of Kenya 1990), and like most dry lands of Kenya, drought conditions are prevalent, some of which have had devastating effects on the environment, the Maasai community and their livestock in the recent past (UNEP \& GOK 2000).

Grasslands, bush land and riverine woodlands are the dominant vegetation associations of the group ranch (Katampoi et al. 1990, Pratt \& Gwynne 1977, Republic of Kenya 1990), some of which are critical habitats for wildlife species that disperse from Amboseli, Chyulu Hills and Tsavo West national Parks. The ranch is recognized as an important wildlife dispersal area and migratory corridor within the Tsavo-Amboseli Ecosystems for species like the Africa elephant (Loxodonta africana), Thompson's gazelle (Gazella thompsoni), Grant's gazelle (Gazella gran-

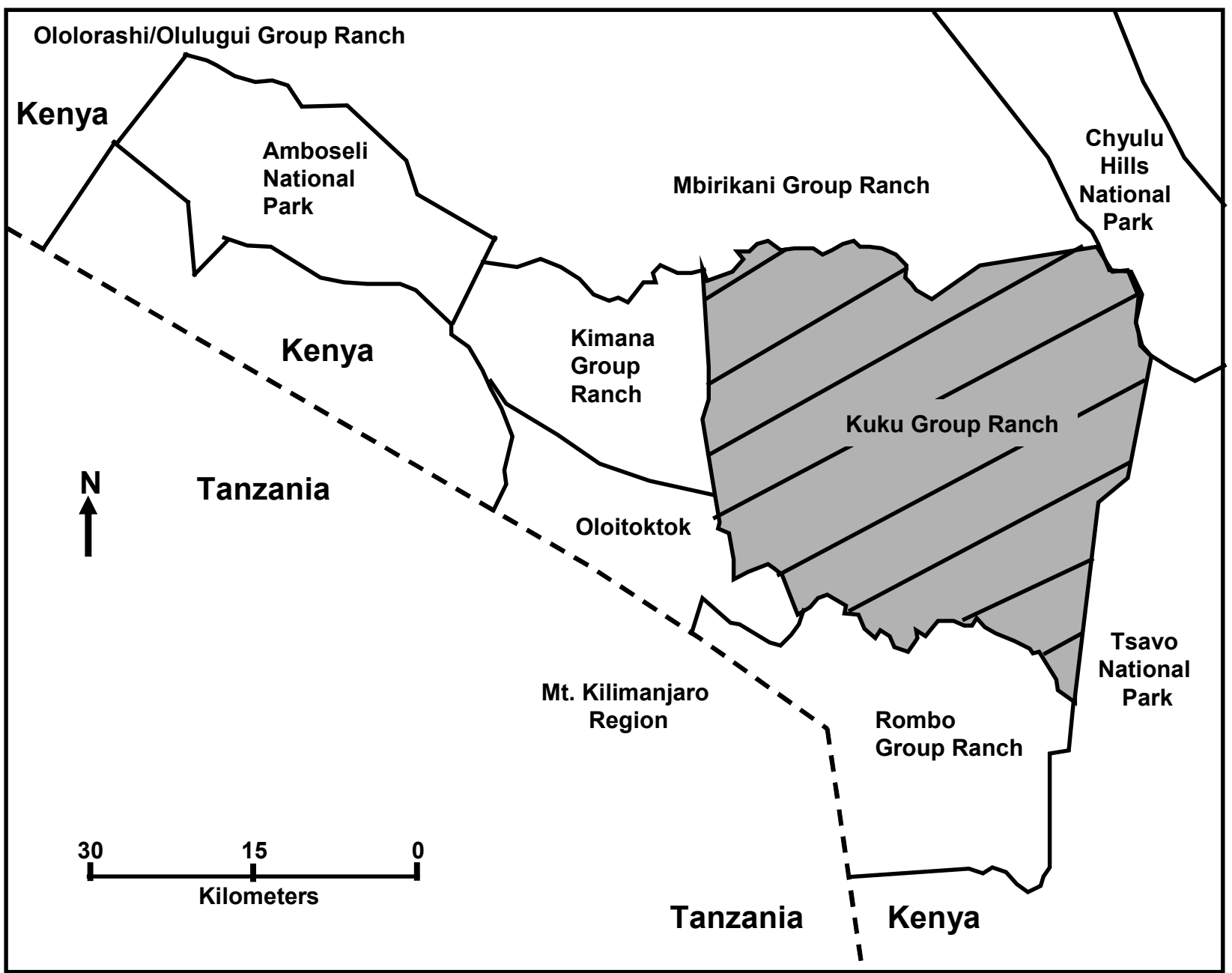

Figure 1. The Tsavo-Amboseli ecosystem showing national parks and the group ranches. 
ti), Maasai giraffe (Giraffa camelopardalis) among many other wild ungulates and carnivores.

Soils in Kuku and the rest of the Amboseli region are mostly of volcanic origin which is associated with the volcanic and tectonic activities that formed the Rift Valley and Mt. Kilimanjaro systems (Awere-Gyekye 1996, Katampoi et al. 1990, Republic of Kenya 1990). Clay and sand constitute the main textural structure of the soils in the region and has profound influence on the their physical and chemical properties and consequently the land use type (s) they can support. These soil characteristics and their poorly developed and un-weathered nature make them unsuitable for agriculture. The ecological conditions of the region based on annual rainfall, rate of evapo-transpiration and poor soil conditions curtail and limit land use practices making traditional livestock production and wildlife conservation the best and most appropriate land use types (Baskin 1994, Pratt \& Gwynne 1977, Republic of Kenya 1990). However, agriculture has become quite prominent not only in Kuku but the entire of the Kajiado District (Campbell et al. 2000, Eliezer 1991, Kiambi 1991, Republic of Kenya 1990). In the recent past, large portions of the ranch especially prime wetlands like swamps and riverine areas were converted to agricultural farms mostly for horticultural crop production exclusively for commercial purposes (Campbell et al. 2000, Eliezer 1991, Kiambi 1991). Rain fed agriculture occurs in the dry rangelands as well, but its expansion has been relatively slow compared to that of wetlands and riverine systems due to; relatively high rates of evapo-transpiration, poor annual rainfall and water holding capacity of the soils. The Maasai people are the dominant tribe in Kuku including the Amboseli region, and for many generations traditional livestock production has been their main source of livelihood. In the recent past this has changed, and the community has increasingly embraced agriculture as a new land use type (Campbell et al. 2000, Eliezer 1991, Kiambi 1991), a practice they have borrowed from the Kamba, Chagga and the Kikuyu, the main tribes that are involved in agriculture in the region.

\section{Materials and methods}

This study was conducted between 2000 and 2002 and used a structured and semi-structured questionnaire to; establish threats to ethno-medicinal plant resources in Kuku Group Ranch, and whether recent cultural and traditional lifestyle changes and practices in the community have had any effect on the use and knowledge of ethnomedicine. To make the data and information representative, the ranch was initially sub-divided into four main sectors within which community members were interviewed in approximately $50 \%$ of the Maasai households. The questionnaires were administered to respondents with the help of local Maasai guides who were familiar with the ranch and Maasai culture and traditions. Similar questionnaires were administered to key informants in the community knowledgeable in traditional medicine, Maasai culture and traditions. During the interview, various aspects of the community culture, traditions and lifestyle in relation to the use and knowledge of ethno-medicine were assessed. In-depth discussions were encouraged and undertaken during such interviews to get more insights into the threats facing medicinal plant resources and use of traditional herbal medicine in the group ranch.

Respondents were asked whether they followed any religion and their level of formal education. These were seen as indicators of exposure to beliefs and practices different from the traditional Maasai culture. It would help establish whether community members exposed to these Western ideologies had different views or perception about traditional medicine, and whether they were less knowledgeable than those who adhered to Maasai cultural and traditions. Occupation or source of livelihood of interviewees was also noted and this was basically for two reasons; livelihoods other than strict pastoralism are a departure from the normal traditional Maasai lifestyle, and agriculture, a rapidly growing land use practice in different parts of the group ranch, was a potential threat to the conservation of indigenous medicinal plant species. The gender of respondents was noted since in Maasai culture, men and women have varying social responsibilities and this might lead to differences in their experience and knowledge on the use of indigenous herbal remedies. Approximate age of respondents was noted and helped to assess their attitude and understanding of traditional medicine, and whether this knowledge was diminishing from generation to generation. In most cases, age was estimated because many respondents did not know their exact age. However, since the local guides were part of the community, and had a good education they were able help make a good guess of the age of the interviewees. Respondents were asked how they learned about traditional plant medicine and whether they were passing on this knowledge to younger generations. This helped to assess whether knowledge of ethno-medicine was being passed from one generation to another.

The impact of using modern medicine on traditional herbal remedies was gleaned by asking respondents whether medicinal plants were the only source of treatment for illnesses and whether they used both modern and traditional medicine. It also helped establish whether modern medicine was readily available and accessible, and whether it was changing knowledge and use of traditional medicine in the community. To determine the depth of knowledge on use of ethno-medicine, respondents who were found to use traditional herbal remedies were requested to name plant species they used and for which treatment. They were also asked to describe the method or procedure of preparation and their level of confidence when preparing and administering them. Finally, respondents were requested to mention potential threats to me- 


\section{Kiringe - Ecological and Anthropological Threats to Ethno-Medicinal Plant Resources and their Utilization in Maasai Communal Ranches in the}

dicinal plant species within the group ranch and whether they had noticed a decline in their availability and abundance. A more in-depth discussion on these threats was undertaken to obtain insights and a clearer picture of the status and future of important medicinal plant resources to the community.

The data obtained during the survey was subjected to appropriate statistical tests and were considered to be significant at an alpha value of 0.05 (Zar 1999). Chi-square goodness of fit test and Chi-square analyses using contingency tables (Zar 1999) were used to test for equality of the responses and access relationships between different community opinions respectively. Correction for continuity in Chi-square tests where one degree of freedom was obtained was done for cases where two categories were compared (Zar 1999).

\section{Results}

There was an equal proportion of male (55\%) and female $(45 \%)$ respondents that were interviewed in this survey $\left(X^{2}\right.$ $=0.871$; d.f. $=1, P=0.351)$, and their ages ranged between 14 and 70 years. A majority of the respondents (81\%) indicated they were Christians and observed its doctrines while the rest $(19 \%)$ claimed they were non-Christians and never practiced or followed its teachings $\left(X^{2}=34.935\right.$; d.f.=1, $P<0.001)$. When asked about their level of education, three quarters or $75 \%$ claimed they had never been to school and lacked exposure on formal education. The rest had been to school and attained different levels of education with $19 \%$ and $3 \%$ having received primary and secondary education respectively. Those with higher education were relatively few, and only $2 \%$ had college level education (e.g. bible school, primary school colleges) the lowest being those with University education (1\%). Different sources of livelihoods or occupations existed among the respondents, with $24 \%$ strictly engaged in traditional pastoralism while $61 \%$ were agro-pastoralists and practiced pastoralism and agriculture. The rest (15\%) were involved in agriculture or crop production. There were significantly more individuals practicing agro-pastoralism than those who were entirely involved in traditional livestock production or agriculture $\left(X^{2}=21.021\right.$; d.f. $\left.=2, P<0.001\right)$.

All of the respondents (irrespective of their age, religion, gender and occupation) had heard about medicinal plants, knew they were used by the community and even used them for treatment of different illnesses and management of various body conditions. However, those who claimed they visited local clinics and dispensaries as an alternative or second choice of health care $(98 \%)$ were significantly more than those who claimed that traditional herbal medicine was their only source of treatment $(2 \%)\left(X^{2}=85.172\right.$; d.f. $=1, P<0.001)$. A significant majority $(73 \%)$ preferred herbal medicine as their primary source of health care, while the rest $(27 \%)$ preferred modern medical care that was provided by government and privately owned health centers $\left(X^{2}=19.882 ;\right.$ d.f. $\left.=1, P<0.001\right)$. Further, those who used both herbal and modern medicine (76\%) were significantly more compared to $21 \%$ and $3 \%$ who exclusively relied on herbal and modern medicine respectively $\left(\mathrm{X}^{2}=\right.$ 78.258; d.f. $=2, P<0.001$ ). When interviewees were asked whether they perceived any dangers associated with use of traditional medicine, there was no significant difference between those who perceived such dangers (41\%) compared to those who claimed it was safe and there were no dangers in its use $(59 \%)\left(x^{2}=3.108\right.$; d.f. $\left.=1, P=0.078\right)$.

Opinions of whom among the community members were responsible for preparing traditional medicine from plants varied across the respondents. A significant majority (71\%) claimed that everybody had the ability to prepare and even administer such medication, another $26 \%$ indicated that only men had these kind of skills and the rest $(3 \%)$ said that there were particular people in the community who were mandated to prepare and administer traditional herbal medicine $\left(X^{2}=66.387\right.$; d.f. $\left.=2, P<0.001\right)$. Similarly, perceptions on the need to teach children or younger generations doctrines of traditional medicine varied across those interviewed. However, majority of them (87\%) had plans or were teaching their children different aspects of Maasai traditional ethno-medicine compared to $13 \%$ who indicated they did have such plans $\left(X^{2}=51.194\right.$; d.f. $=1$, $P<0.001$ ). Interviewees who learnt about medicinal plants and traditional Maasai medicine practices from their parents $(53 \%)$ were significantly more than those said they learnt from elders $(22 \%)$ or other community members $(25 \%)\left(X^{2}=15.935\right.$; d.f. $\left.=2, P<0.001\right)$. Chi-square analyses showed that the number of medicinal plant species that respondents indicated they were used for medicinal purposes by the community was dependent of their age (Chi-square contingency table, $X^{2}=44.915$; d.f. $=9$, $P=0.066$ ) and gender (Chi-square contingency table, $X^{2}$ $=16.022$; d.f. $=18, P<0.001$ ), but independent of religious status (Chi-square contingency table, $X^{2}=5.244$; d.f. $=9$, $\mathrm{P}=0.812$ ), occupation (Chi-square contingency table, $\mathrm{X}^{2}$ $=14.124$; d.f. $=18, P=0.589$ ) and level of education (Chisquare contingency table, $X^{2}=17.080$; d.f. $=27, P=0.929$ ).

When asked whether there was an overall notable decline in the availability and abundance of medicinal plants in the ranch, a significantly higher number of respondents $(69 \%)$ claimed that such a change had not occurred compared to $31 \%$ who indicated there has been a decline over the years $\left(X^{2}=13.172\right.$; d.f. $\left.=1, P<0.001\right)$. On the potential threat factors facing ethno-medicinal resources in the group ranch, over fifty percent of respondents (56\%) indicated that they were not aware of such threats though they were not significantly different from those who indicated they were aware of these threats $(44 \%)\left(X^{2}=1.301\right.$; d.f. $=1, P=0.254)$. However, the households mentioned different types of threats facing medicinal plants across the group ranch. Charcoal burning was considered by $50 \%$ of the households to be a serious threat, while introduc- 
tion of agriculture and its expansion to different parts of the ranch was mentioned by $41 \%$ of the households. Other frequently mentioned threat factors were; over-population (28\%) and recent climatic changes (25\%) particularly frequent and sometimes prolonged drought conditions which they claimed affected natural regeneration of both medicinal and non-medicinal plants including their recovery from overuse. Over-exploitation of medicinal plants by community members and loss of indigenous knowledge on the value and use of medicinal plant resources was blamed by $11 \%$ and $8 \%$ of the households respectively, while $49 \%$ felt that a combination of different factors was responsible for the decline of medicinal plants in the ranch.

\section{Discussion}

There is increasing concern that introduction of Western ideologies in Maasailand including Kuku Group Ranch will erode and replace their traditional lifestyle and cultural practices. In spite of this, most members irrespective of their age, gender, education, religion and occupation had some basic knowledge of traditional ethno-medicine and most admitted it was their preferred choice of treatment. Though Western medical care has been introduced in the ranch and its environs, most community members only visited locally available health centers as a last resort when herbal medicine failed. The findings of this study somehow contradict the assumption that given a choice, local communities would prefer modern over their traditional medicine. Several factors can account for the high dependency on traditional over Western medicine in Kuku Group Ranch. Traditional medicine unlike modern medicine is an integral component of Maasai culture which has evolved for many generations, and it is considered effective in treating and managing certain cultural health problems (Sindiga 1995). It is efficacious, readily acceptable by the community and is holistic in its approach to addressing health problems. Further, it is cost effective and traditional healers charge affordable fees, is readily available and accessible to rural communities even where infrastructure is poor (Phillips 1985, Pillsbury 1979, Sindiga 1995, WHO 1978). Dependence on traditional medicine can also be attributed to a strong attachment to their traditional lifestyle, high level of poverty in the community, remoteness of the area coupled by very poor infra-structure which make access to modern health facilities difficult. Contrary to the belief by modern medical practitioners, most rural communities of Africa including the Maasai do not see any dangers associated with the use of herbal remedies. A majority are actually suspicious of Western medicine partly because it does not tolerate local beliefs and behavior related to causal factors for health related problems (Sindiga et al. 1995). Local people can easily communicate with their traditional medicine men or healers and trust that the medication they give them is effective since its has been known to work for many generations. Most of the medicinal plants are locally available and readily accessible within the ranch and in most cases at no cost, or when they are bought in the local markets, they are affordable. Medicinal plants are also considered to be locally abundant and allow some degree of home treatment even though more experienced and specialized traditional healers can be consulted whenever a need arises. On the other hand modern medical care has certain requirements that cannot always be met such as a sanitary environment, ability of patients to pay for treatment and distribution of medical supplies. In spite of the ongoing campaign by the Kenya Government and non-governmental organizations to popularize modern medical care in the Loitokitok region for which Kuku Group Ranch is part of, it might take many more years before the community fully accepts this form of medical treatment as opposed to their traditional primary health care.

The fact that nearly all community members could prepare traditional herbal medicines indicates that this practice is entrenched in the community. It also shows that skills of using locally available ethno-medicinal plant resources are nurtured in the entire community irrespective of gender and age. Sindiga (1995) concurs that use and basic knowledge on traditional medicine is deeply rooted among the Maasai people even though there are professionally recognized healers (labaak, sing. olbaani) in the society who are mostly consulted when home treatment fails. The number of plants that respondents mentioned they were of medical value was dependent on gender. Some respondents insinuated that only men were knowledgeable enough to prepare and administer traditional herbal medicine. In the Maasai community, women are held with low esteem and are usually excluded on important traditional and cultural aspects of the society including learning various aspects herbal medicine (Sindiga 1995c). This can partly account for the notion that men were more equipped on ethno-medicinal skills compared to women.

Most of the respondents were willing to teach their children about traditional herbal medicine. This conforms to the traditional Maasai norms where every youth irrespective of their gender is expected to learn the medicinal value of different plant species found in their environs as they mature (Sankan 1971). Normally young girls learn from older women especially their mothers and grandmothers (Sindiga 1994) while boys are more likely to acquire this knowledge from older men in the community. As girls and boys mature they get more exposure to other societal traditions and practices including more complex aspects of herbal medicine. It is therefore not surprising that irrespective of their gender or age, all respondents had some basic knowledge of locally used medicinal plants, and the Maasai traditional healing practice in general. The number of medicinal plants mentioned by the interviewees which was taken to represent their knowledge of ethno-medicine was dependent on their age. The younger generation appeared to know relatively fewer plant species that were of medicinal value compared to junior elders and the elderly members in the community. This could possibly indicate a general loss of this kind of knowledge among the youth due to a tendency to stray 


\section{Kiringe - Ecological and Anthropological Threats to Ethno-Medicinal Plant Resources and their Utilization in Maasai Communal Ranches in the}

away or even shun traditional Maasai practices, or it could simply be a reflection of the way community members generally gather and acquire more and more knowledge on traditional medicine throughout their lives as they mature. However, nearly all the elders interviewed during the survey cited a general lack of interest on Maasai traditional medicine skills as the primary reason for loss of ethnomedicinal skills among the younger generation. They felt that the youth had little respect for Maasai traditions and culture including ethno-medicine whose vast knowledge is held by the elder members of the community and their culture as a whole. As already mentioned, every person in the Maasai family and by extension the entire community are exposed to their traditions and culture such as use of ethno-medicine right from their childhood, a skill that is nurtured as they grow and mature to elders but this could be changing in Kuku Group Ranch.

The notion that formal Western education would affect traditional lifestyle among the Maasai including knowledge and use of traditional herbal remedies was not found to be the case in Kuku. People with a good education especially secondary level and above are more exposed to other cultures and are more likely to abandon their traditions and lifestyles like use of traditional medicine. They spend more time out of their homes and their interaction with other members of the community through which they could learn their culture and traditions is to a certain extent compromised. Illiteracy level in the community and in Maasailand in general is very high with very few people having attained secondary or higher education and this could partly explain why education appeared to have had little impact on knowledge of ethno-medicine. Although formal education had not affected knowledge of ethno-medicine in the ranch, its future contribution to erosion and collapse of their primary health care system cannot be overlooked. Some of the older people interviewed during the study felt there was a general lack of respect and interest (in Maasai traditional medicine and other traditions and practices) among the young people especially those who had had formal education.

The finding that most of the respondents were Christians and admitted practicing its doctrines was an indication that religion especially Christianity has become part of the Maasai community in Kuku Group Ranch. Some even claimed they were born again Christians, a belief that has become prevalent among other Christianity practicing tribes of Kenya. This study found that the number of plants that respondents mentioned they were of medicinal value was independent of their religious status. It could be an indicator that Christianity did not have significant impact on knowledge of traditional herbal medicine among community members. This study did not investigate the rate of spread of Christianity across the community or even the rate at which they were getting converted. However, the fact that majority of the interviewees were Christians and the observation that there was a rapid mushrooming of churches across most of the group ranch is to an extent an indicator that Christianity is taking hold in the community and possibly at a faster rate than it was a couple of years ago. If indeed more members were converting to Christianity and believed in its teachings and doctrines, it is most likely they will eventually abandon their cultural and traditional beliefs and practices.

The collapse of the Kikuyu traditional healing system can be used to illustrate the probable impacts of Christianity and modern medicine in Kuku Group Ranch. According to Brown (1995) the advent of Christianity and colonialism in Kenya severely affected and transformed the socio-cultural fabric of local indigenous communities. One of the main campaigns by missionaries was to demonize and abolish African tradition and cultural beliefs which they considered to be barbaric, backward, unclean and ungodly ( Brown 1995; Sindiga et al. 1995b; Fratkin 1996). Witchcraft, use of traditional medicine and any other traditional beliefs and practices were vigorously discouraged especially among those who had converted to Christianity. Western lifestyles and believes like use of modern medicine were also popularized with the notion that they were more advanced, godly and even superior over African culture and traditions.

The impact of Christianity on local African tribes became quite apparent among certain communities in Kenya especially the Kikuyu's in the early years of the 20th century which saw most of their cultural beliefs and traditions including use of ethno-medicine significantly change (Sindiga et al. 1995a). Another notable and fundamental change in the community was establishment of modern health facilities by the colonial administrators (Sindiga 1990). At the same time, Christian churches particularly the Roman Catholic, Church of Scotland Mission and Church Missionary Society established themselves across most of Kikiyuland where they set-up churches and more health facilities. The combined effort of the colonial masters and Christian preachers launched a strong campaign against Kikuyu culture and traditions among them being use of traditional medicine (Sindiga 1990). Further efforts to legitimize use of Western health system was reinforced by the introduction of the Witchcraft Act of 1925 (Revised later in 1962) by the government and whose main aim was to protect Kenyans from intimidation by witch doctors (Sindiga 1990). Following the negative tag associated to Kikuyu traditional medical practices, most of them especially those who were Christians ended up concealing their visits to traditional practitioners in a desperate attempt to avert any conflict with elite fellow Christians or the colonial administrators. With time the Kikuyu's accepted Western medical care system and it is currently widespread among the community and their traditional medicine practices and knowledge more or less collapsed (Sindiga et al. 1995a). The erosion and collapse of their knowledge and use of medicinal plants due to colonial stereotypes combined with influence of the missionaries on their traditions and 
cultural practice is yet to be overcome in contemporary Kikuyu society (Sindiga et al. 1995a). Good et al. (1980) noted that rural traditional medicine in the community is in the process of serious decay and the elderly people with this kind of knowledge represent the very last members of the past generation and are disappearing through natural attrition. A notable observation is that Kikuyu Christians are strongly opposed not just to the use of traditional medicine but also other beliefs that try to explain the causes of illnesses and the role of traditional healers. It should suffice to say that in the last 100 years, Kikuyu land has undergone through tremendous socio-economic changes and their culture has not been spared either and this has responsible for the erosion and collapse of their traditional health system. The collapse of Kikuyu traditional healing system is a clear indicator of how misunderstanding the value and role of African traditional ethno-medicine by Christian missionaries and the colonial administrators can lead to loss of valuable, workable and reliable systems in most African societies (Thairu 1975). Although the Maasai community in Kuku had immense knowledge on traditional medicine and its use was quite prevalent and entrenched in the society, its future could be at stake. Introduction of Christianity and Western medicine and health facilities did not discourage the community from using traditional medicine or even teaching younger generations aspects of this primary health care system. However, if the effects of Christianity and introduction of modern health care in Kikuyu land are anything to go by, it is most likely that the next few decades will see a gradual and significant erosion and collapse of their traditional ethno-medicinal knowledge, beliefs, and practices.

The Maasai are generally a pastoral community whose livelihood is dependent on traditional pastoralism. This has changed in the recent past across Maasailand (Seno \& Shaw 2002) as well as Kuku Group Ranch and more community members are now engaging in other activities such as agriculture either to supplement their income or provide more food for their families. The finding that majority of the interviewees were agro-pastoralists confirms past research findings which have demonstrated that agriculture has become an important land use type in Kuku and Loitokitok region as a whole (Campbell et al. 2000, Eliezer 1991, Kiambi 1991, Republic of Kenya 1990). It is generally believed that members who abandon pastoralism are less likely to adhere to Maasai traditions and cultural value such as use of traditional medicine. However, this was not found to be the case and irrespective of their occupation members of the ranch were still heavily dependent on herbal medicine and had immense knowledge on plant species that were valued by the community due to their medicinal properties. Occupation alone many not account for this but its highly probable that a combination of factors could help account for this trend.

The fact that most members of Kuku have noticed a decline in the abundance and availability of medical plants is an issue of concern that needs to be addressed. Consid- ering the level of poverty in the community, the number of available clinics and dispensaries and poor infrastructure which hampers access to modern health facilities, loss of medical plants would have a profound effect on the primary health system that currently serves the community. Apart from this loss, the community stands to suffer another loss since they are heavily dependent on trees and shrubs, some of which are used for other uses like wood fuel, construction of houses and fencing of livestock sheds and homesteads (Kiringe \& Okello 2005). Kiringe and Okello (2005) found out that the community used approximately 24 species of trees and shrubs for different purposes including ethno-medicine. Firewood was found to use large quantities of locally available trees and shrubs followed by fencing and construction of houses. The study also found that group ranch members had noticed and even shown great concern on the decline or tree and shrubs cover. The observed decline in medicinal plants was attributed to a number of factors including charcoal burning, agriculture, increase in human population and drought conditions. Others were a combination of factors, loss of indigenous knowledge on the role and value of ethno-medicinal plants and their over exploitation mostly for commercial purposes. One of the threats that was of great concern to the members is charcoal burning for commercial purposes which according to Kiringe and Okello (2005) appeared to target Acacia mellifera, A. tortillis and A. xanthophloea which coincidently have some medicinal use. Herlocker (1999) concurs that charcoal burning was absent in Maasailand but it has become prevalent as one of the alternatives which can be used by local communities to supplement their meager income from other economic activities. The destructive effects of charcoal production in the group ranch is likely to escalate. It could have increased due to the rapidly mushrooming market centers in the Amboseli region which consume more charcoal as well as the demand in centers along the Mombasa highway and far big urban centers like Nairobi and Mombasa town. In their study, Kiringe and Okello (2005) found that decline of trees and shrubs in Kuku was due to a number of factors including but not limited to agriculture expansion, increase in human settlements (sedentarization), over grazing by livestock and an increased demand on plant resources for various purposes by the community. Further research is needed to evaluate the availability and abundance of medicinal plants in the ranch, and also elucidate the contribution of the different threat factors to the decline of these vital resources.

\section{Conclusion}

This study has shown that knowledge of traditional medicine in Kuku Group Ranch is still prevalent and is the most preferred form of medical care in spite of introduction and exposure to Western ideology and lifestyle. Overall, it appears that the threats hypothesized to be affecting the transfer of knowledge of traditional herbal remedies from 


\section{Kiringe - Ecological and Anthropological Threats to Ethno-Medicinal Plant Resources and their Utilization in Maasai Communal Ranches in the}

generation to generation, or the use of traditional medicine within a generation, does not seem to have had significant impact. Christianity, gender, modern medical care, occupation and education appear to have little effect on knowledge of ethno-medicine. However, these factors could be combining with a general inclination to Western culture to divert people's interests from traditional medicine and traditions and cultural practices. Taking into cognizance that Western culture and lifestyle have eroded the social and traditional fabric of most Africa societies including most tribes of Kenya, more detailed research is needed in Kuku to elucidate the effects of Western culture on Maasai traditional ethno-medicine beliefs and practices.

Although there is an emphasis on the superiority of Western over traditional medicine, it is possible that elements of both practices can be incorporated in a manner that would optimize on the strengths of the two. Availability of herbal plant remedies and their effectiveness, combined with diagnostic approach and facilities of Western medicine and its ability to treatment certain types of ailments untreatable using ethno-medicine, would be extremely beneficial for most rural communities. The World Health Organization (WHO) is trying to implement a program that attempts this cause (Maurice 1993, Olayiwola 1987) particularly in the less developed countries including Kenya. In the same breath, the Kenya Government has in the recent past tried to incorporate some useful aspects of traditional African medicine into the national medical health system amidst a lot of resistance form medical doctors. However, if the approach is accepted and eventually becomes successful, then the changing lifestyles and traditional practices of the current generation of most tribes of Africa including the Maasai may not have a fundamental effect on the current loss of use and knowledge of traditional used medicine. Western medicine can greatly benefit from indigenous knowledge of locally available ethno-medicinal resources. The potential for development of new plant-based drugs can equally promote their conservation and habitats in place like Kuku where such resources are still readily available. Further, since so many people in the community depend on medicinal plants, they must be protected. It is possible that an effective method of promoting conservation is by encouraging the use of medicinal plants and thus increasing their perceived value. To enhance the conservation of medicinal plant resources in the ranch and mitigate their perceived decline, appropriate conservation measures, monitoring and harvesting strategies by the community are strongly recommended.

\section{Acknowledgements}

Thanks to all past SFS-Center for Wildlife Management Studies students especially those who did their Wildlife Ecology Directed Research between 2000 and 2002 under my guidance. I also sincerely thank the local Maasai guides who spent a lot of their time with me in the field interviewing members of Kuku Group Ranch. I cannot forget to thank Dr. Simon ole Seno our Center Director for his support and encouragement during the many hours that I spent in the field conducting interviews. I do appreciate the logistical and financial support he jointly provided with The School for Field Studies in the United States of America. Finally, I feel greatly indebted to the anonymous reviewers who helped shape this paper thorough their valuable comments and suggestions.

\section{Literature Cited}

Awere-Gyekye, K. 1996. Land use planning and coordination study: national land use patterns and trends. Pp. 43-49 in Final report to the Kenya Wildlife Service. Kenya Wildlife Service.

Barrow, E.G.C. 1996. The Dry Lands of Africa: Local participation in tree management. Initiatives Publishers, Nairobi.

Baskin, Y. 1994. There is a new wildlife policy in Kenya: Use it or lose it. Science 265:733-734.

Brown, K. 1995. Medicinal plants: indigenous medicine and conservation of biodiversity in Ghana. Pp. 201-231 in Intellectual Property Rights and Biodiversity Conservation. Edited by T. Swanson. Cambridge University Press, London, U.K.

Campbell, D.J., H. Gichohi, A. Mwangi \& L. Chege. 2000. Land use conflict in Kajiado District, Kenya. Land Use Policy 17:337-438.

Good, C.M, V. Kimani \& J.M. Lawry. 1980. Gukunura mundu mugo: the initiation of a medicine man. Anthropos 75:87-116.

Eliezer, W. 1991. Rombo: Farming example worth modeling after. Kajiado Focus. Issue 1.

Farnsworth, N.R. \& D.D. Soejarto. 1991. Global importance of medicinal plants. Pp 25-43 in The Conservation of Medicinal Plants. Edited by A. Olayiwola, H. Vermon \& $\mathrm{S}$. Hugh. Proceedings of an international consultation, 2127 March 1988 held at Chiang Mai, Thailand. Cambridge University Press.

Fratkin, E. 1996. Traditional medicine and concepts of healing among Samburu pastoralists of Kenya. Journal of Ethnobiology 16:63-97.

Githae, J.K. 1995. Ethno-medical practice in Kenya: the case of Karati Rural service center. Pp 55-63 in Traditional Medicine in Africa. Edited by I. Sindiga, C. Nyaigotti-Cha- 
cha \& M.P. Kanunah. East African Educational Publishers Ltd., Nairobi.

Katampoi, K.O., G.O. Genga, M. Mwangi, J. Kipkan, J.O. Seitah, M.K. van Klinken \& M.S. Mwangi. 1990. Kajiado District Atlas. ASAL Programme Kajiado, Nairobi.

Kiambi E 1991. Horticulture: Loitokitok leads the pack. Kajiado Focus. Issue 1.

Kiringe, J.W. \& M.M. Okello. 2005. Use and availability of tree and shrub resources on Maasai communal rangelands near Amboseli, Kenya. African Journal of Range \& Forage Science 22:37-46.

Kiringe, J.W. n.d. A survey on the use of ethno-medicinal health remedies among the Maasai of Southern Kajiado District, Kenya. Manuscript with author.

Maurice, M.I. 1993. Handbook of African Medicinal Plants. CRC Press, Boca Raton, Florida.

Ochieng' Obado, E.A. \& J.A. Odera. 1995. Management of medicinal plant resources in Nyanza. Pp. 153-167 in Traditional Medicine in Africa. Edited by I. Sindiga, C. Nyaigotti-Chacha \& M.P. Kanunah. East African Educational Publishers Ltd., Nairobi.

Olayiwola, A. 1987. The best of both worlds: bringing traditional medicine up to date. Social Science and Medicine 24(2): 177-181.

Olayiwola, A. 1991. Medicinal plants: policies and priorities. Pp. 3-11 in The Conservation of Medicinal Plants. Edited by A. Olayiwola, H. Vermon \& S. Hugh. Proceedings of an international consultation, 21-27 March 1988 held at Chiang Mai, Thailand. Cambridge University Press, Cambridge.

Phillips, D.R. 1985. Directions for Medical Geography in the 1980s: Some observations from the United Kingdom. Social Science and Medicine 20:404-407.

Pillsbury, B.L.K. 1979. Reaching the rural poor: Indigenous health practitioners are there already. AID Programme Evaluation Discussion Paper No. 1. USAID, Washington, D.C.

Pratt, D.J. \& M.D. Gwynne. 1977. Rangeland Management and Ecology in East Africa. Hodder and Stroughton, London, U.K.

Republic of Kenya. 1990. Kajiado District Atlas. ASAL Programme Kajiado, Ministry of reclamation and development of Arid, Semi-Arid Areas and Wastelands. Kajiado, Kenya.
Sankan, S.S. 1971. The Maasai. Nairobi. East African Literature Bureau, Nairobi.

Sankan, S.S. 1995. The Maasai. Kenya Literature Bureau, Nairobi.

Sheldon, J.W. \& M.J. Balick. 1995. Ethno-botany and the search for balance between use and conservation. Pp 3657 in Intellectual Property Rights and Biodiversity Conservation. Edited by T. Swanson. Cambridge University Press, London, U.K.

Sindiga, I. 1990. Health and disease. Pp. 133-144 in Themes in Kenya History. Edited by W.R. Ochieng. Heinemann, Nairobi.

Sindiga, I. 1994. Indigenous medical knowledge of the Maasai. Indigenous knowledge and development monitor 2:16-18

Sindiga, I. 1995a. Traditional medicine in Africa: An introduction. Pp. 1-15 in Traditional Medicine in Africa. Edited by I. Sindiga, C. Nyaigotti-Chacha \& M.P. Kanunah. East African Educational Publishers Ltd., Nairobi.

Sindiga, I.1995b. African ethno-medicine and other medical systems. Pp. 16-27 in Traditional Medicine in Africa. Edited by I. Sindiga, C. Nyaigotti-Chacha \& M.P. Kanunah. East African Educational Publishers Ltd., Nairobi.

Sindiga, I. 1995c. Maasai traditional medicine. Pp. 94-107 in Traditional Medicine in Africa. Edited by I. Sindiga, C. Nyaigotti-Chacha \& M.P. Kanunah. East African Educational Publishers Ltd., Nairobi.

Sindiga, I. 1995d. Gusii traditional medicine. Pp. 108-116 in Traditional Medicine in Africa. Edited by I. Sindiga, C. Nyaigotti-Chacha \& M.P. Kanunah. East African Educational Publishers Ltd., Nairobi.

Sindiga, I. 1995e. Managing illness among the luo. Pp. 64-79 in Traditional Medicine in Africa. Edited by I. Sindiga, C. Nyaigotti-Chacha \& M.P. Kanunah. East African Educational Publishers Ltd., Nairobi.

Sindiga, I., M.P. Kanunah, E.M. Aseka \& G.W. Kiriga. 1995a. Kikuyu traditional medicine. Pp. 129-139 in Traditional Medicine in Africa. Edited by I. Sindiga, C. NyaigottiChacha \& M.P. Kanunah. East African Educational Publishers Ltd., Nairobi.

Sindiga, I., M.P. Kanunah, C. Nyaigotti-Chacha \& E.S. Mwangola. 1995b. The future of traditional medicine in Africa. Pp. 175-183 inTraditional Medicine in Africa. Edited by I. Sindiga, C. Nyaigotti-Chacha \& M.P. Kanunah. East African Educational Publishers Ltd., Nairobi. 


\section{Kiringe - Ecological and Anthropological Threats to Ethno-Medicinal Plant Resources and their Utilization in Maasai Communal Ranches in the}

Seno, S.K. \& W.W. Shaw. 2002. Land tenure policies, Maasai traditions, and wildlife conservation in Kenya. Society and Natural Resources 15:79-88.

Southgate, D. \& J. Sanders. 1990. Resource degradation in Africa and Latin America: Population pressure, policies, and property arrangements. American Journal of Agricultural Economics 72:1259-1264.

Thairu, K. 1975. The African civilization. East African Literature Bureau, Nairobi.

United Nations Environment Programme (UNEP) and Government of Kenya (GOK) .2000. Devastating Drought in Kenya: Environmental impacts and responses. Prepared by United Nations Environment Programme and Government of Kenya, Nairobi.

Wandibba, S. 1995. Traditional medicine among the Abaluyia. Pp. 117-128 in Traditional Medicine in Africa. Edited by I. Sindiga, C. Nyaigotti-Chacha \& M.P. Kanunah. East African Educational Publishers Ltd., Nairobi.

Were, G.S. \& C.L. Wanjala. 1986. Editors of Kajiado District: Socio-Cultural Profile. A joint research and training project of the Ministry of Planning and National Development and the Institute of African Studies, University of Nairobi, Nairobi.

World Health Organization (WHO). 1978. The Promotion and Development of Traditional Medicine. Report of a WHO meeting N0. 622. WHO, Geneva.

Zar, J. 1999. Biostatistical Analysis. Fourth edition. Prentice-Hall, Inc. Englewood Cliffs, New Jersey. 
